\title{
Application of Werner Deconvolution Method in the Direct Interpretation of Residual Aeromagnetic Anomalies
}

\author{
Usman N. ${ }^{1}$ Lawal K. M. ${ }^{2}$ and Aku M. O. ${ }^{3}$ \\ ${ }^{1}$ (Department of Physics, Umaru Musa Yar'adua University, Katsina, Nigeria) \\ ${ }^{2}$ ( Ahmadu Bello University, Zaria) \\ ${ }^{3}$ (Department of Physics, Bayero University Kano, Nigeria)
}

\begin{abstract}
The total field aeromagnetic contour map located between geographic latitude $11^{0} 00^{\prime} \mathrm{N}$ to $11^{0} 30^{\prime} \mathrm{N}$ and longitude $7^{0} 30^{\prime} E$ to $8^{0} 00^{\prime} E$ was acquired, digitized and residualized in order to assess the Werner deconvolution method in the interpretation of geophysical data. Three profiles were selected for the interpretation of residual aeromagnetic anomalies. The result obtained from the data of Zaria area using Werner deconvolution method was filtered and shows that the depth to magnetic source values vary from 0.1 to $2.6 \mathrm{~km}$ below the ground surface indicating the shallow nature of the magnetic source, while the susceptibility vary from $6.7 \times 10^{-5}$ to 2.193 S.I unit approximately. The result obtained shows much correlation with some of the geophysical works carried out in the study area. The method is found to be simple, past and very effective.
\end{abstract}

Key words: Aeromagnetic anomaly, Werner deconvolution, Depth to magnetic source and Susceptibility

\section{Introduction}

Aeromagnetic survey are widely use for investigating large area because of the high speed of operation, high sensitivity of the measuring instrument and it is cheap for investigating large area [1]. The data obtain from aeromagnetic survey is processed using computer techniques in order to remove noise and then transformed into contour map as aeromagnetic anomalies. Economically important rock and mineral can be identified by the knowledge of magnetic susceptibility and the corresponding depth from the ground surface is of vital importance in mineral prospecting. The depth to source can also be use to establish basement depth which is also needed in oil and gas prospecting.

So many geophysical works using different methods of exploration have taken place in the study area and its environs. A ground Magnetic investigation in the Kubani River Basin Zaria, was conducted; the quantitative interpretation of the residual anomaly map shows a maximum depth to basement value of $52.5 \mathrm{~m}$ around Unguwan Maigamo village [2]. Reduction to the pole technique was applied to the aeromagnetic data of Zaria area; the depth to the top of $1.8 \mathrm{~km}$ and $4.3 \mathrm{~km}$ was estimated with the minimum susceptibility of 0.001972 and 0.002545 S.I unit respectively. The anomalies analyzed are granitic in nature [3]. The major mineral controlling the magnetic susceptibility in the Kufena hill is biotite and the magnetic susceptibility value vary between $6.1 \times 10^{-5}$ and $8.5 \times 10^{-5}$ S.I units [4].

This research is carried out in order to assess the Werner deconvolution method in the interpretation of geophysical data. The method separate an anomaly from the interference caused by adjoining anomaly, this will ensure accurate result. It provides vital information of the causative anomalous body such as depth to the top, susceptibility contrast and the dip. The objectives of this research work are to estimate the susceptibility, dip and depth to magnetic source.

Location of the study area: The area of study is the Zaria area of Kaduna state, north western part of Nigeria. The area is located between geographic latitudes $11^{\circ} 00^{\prime} \mathrm{N}$ to $11^{\circ} 30^{\prime} \mathrm{N}$, and longitude $7^{0} 30^{\circ} \mathrm{E}$ to $8^{0} 00^{\prime} \mathrm{E}$ within the Northern Nigerian Precambrian belt. It is within geological and aeromagnetic map sheet 21 and sheet $102[5,6]$ respectively within an area of approximately $3025 \mathrm{~km}^{2}$.

\section{Materials And Methods}

The aeromagnetic map of Zaria area [5], on a scale of 1:100,000, was obtained from Geological Survey of Nigeria (G.S.N) and digitized. The total magnetic field intensity (Figure 1) consists of two components; regional and residual field. Polynomial fitting of the first order is employed in this research in order to separate the two components. The trend surface equation obtained using Surfer V. 7.0 software is

$\mathrm{Z}(\mathrm{X}, \mathrm{Y})=\mathrm{A} 00+\mathrm{A} 01 \mathrm{Y}+\mathrm{A} 10 \mathrm{X}$

Where $\mathrm{Z}(\mathrm{X}, \mathrm{Y})$ is the regional field, $\mathrm{X}$ and $\mathrm{Y}$ are geographic coordinates of the map. $\mathrm{A} 00, \mathrm{~A} 01$ and $\mathrm{A} 10$ are the polynomial regression coefficients with values 8356.8421 ,

-25.7602 , and -25.3758 respectively. Substituting the above coefficients into equation (1) we have

$$
\mathrm{Z}(\mathrm{X}, \mathrm{Y})=8356.8421-25.7602 \mathrm{Y}-25.3758 \mathrm{X}
$$


The regional field values obtained from equation 2 was then subtracted from the corresponding total field value and residual field is obtained. The residual field is the component of the magnetic field which represents the effect of near surface bodies. The values of the residual field together with the respective geographical coordinates were then map as shown in Figure 2.

Theory of the computational method: The equation of the total magnetic field for a thin dike with infinite strike length and depth extent can be written in the form as

$$
\mathrm{F}(\mathrm{x})=\frac{A\left(x-x_{0}\right)+B z}{\left(x-x_{0}\right)^{2}+z^{2}}
$$

Where $\mathrm{x}_{0}$ is the surface point directly above the center of the top of the dike, $\mathrm{x}$ is the point of measurement and $\mathrm{x}$ axis is normal to the strike, and $\mathrm{z}$ is the depth to the top. A and $\mathrm{B}$ are functions of the dike geometry mineralization

$$
x^{2} F=-A x_{0}+B z+A x+2 x_{0} x F-x_{0}^{2} F-F z^{2}
$$

So that equation (3) becomes

$x^{2} F(x)=a_{0}+a_{1} x+b_{0} F(x)+b_{1} x F(x)$

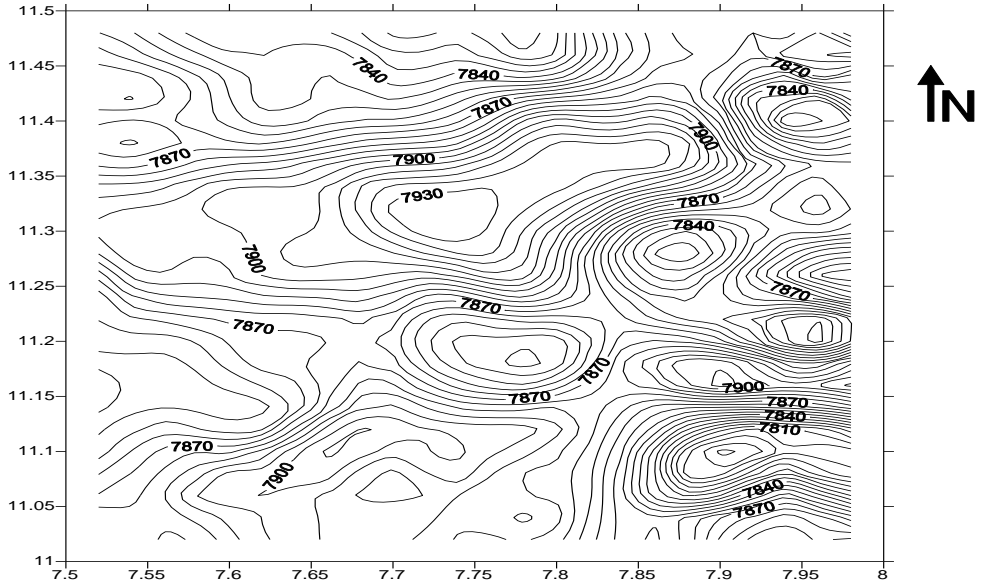

Legend: $7870 ~ \sim$ a contour line showing magnetic field intensity, 7870nT

Figure 1: Total aeromagnetic anomaly map (contour interval $\sim 6 \mathrm{nT}$ )

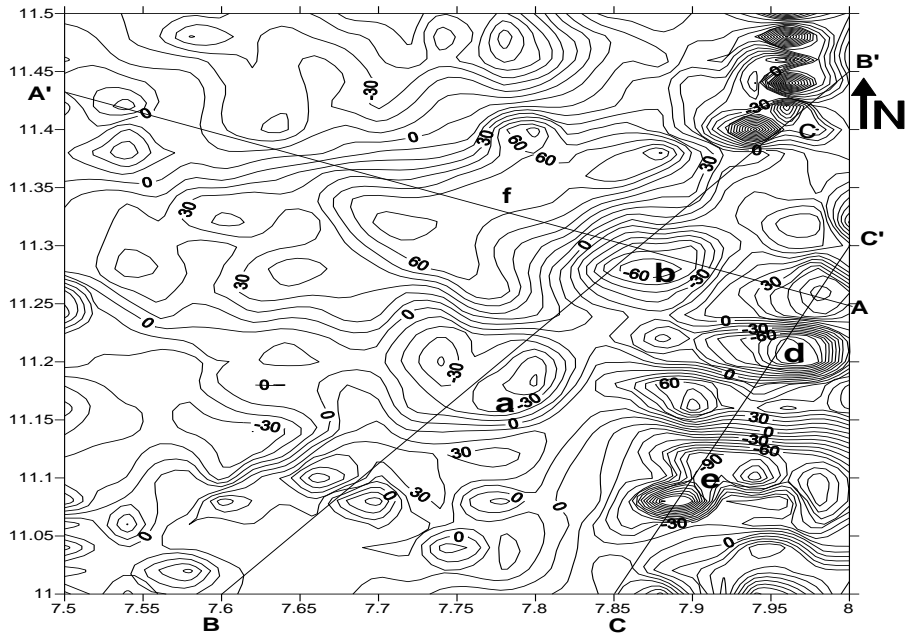

Scale 1:360,000

Legend: $\sim 30 \sim$ a contour line showing magnetic field intensity, 30nT

Figure 2: Residual aeromagnetic anomaly map with selected profiles; AA', BB' and CC' (contour interval $\sim 10 \mathrm{nT}$ ) 
The depth $(\mathrm{z})$ and the surface point directly above the center of the top of the dike (x) can be determined from the solution of equation (4) using the relation $x_{0}=\frac{1}{2} b_{1}$ and $z= \pm \frac{1}{2} \sqrt{-4 b_{0}-b_{1}^{2}}$. The susceptibility and dip can be obtained from the functions A and B.

If we now admit the possibility of interference and assume that the interference can be represented by a polynomial of some degree, we can add the interference polynomial to equation (3).

$\mathrm{F}(\mathrm{x})=\frac{A\left(x-x_{0}\right)+B z}{\left(x-x_{0}\right)^{2}+z^{2}}+C_{0}+C_{1} x+\cdots+C_{n} x^{n}$

Where $\mathrm{n}$ is the order of the interference polynomial and C's are the coefficients. We now have total of $(n+5)$ unknowns and therefore $(n+5)$ equations; and $(n+5)$ points are required to solve for the unknowns [7].

\section{Result And Discussion}

Figure 2 shows the residual aeromagnetic map of Zaria area where three (AA', BB' and $\left.\mathrm{CC}^{\prime}\right)$ profiles were selected for the quantitative interpretation in order to estimate the distance along the profile to the center on the top of the dike, depth, dip and susceptibility of the causative body using Werner deconvolution technique mentioned above when the sources are assume to be dike and contact.

The three profiles shown in figure 2 have been analyzed using a computer program similar to the one used by Umego, Magdep [8]. It is also similar to the one described by Jain [9]. The result obtained was then filtered with anti aliasing filter using the parameter of 3 . The summary of the result obtained are given in the following tables.

Profile AA': This profile passes through an area of relatively high magnetic anomalies through an elongated contour $\mathbf{f}$ in the northern part of the map. The maximum magnetic intensity value along this profile is $70 \mathrm{nT}$ and minimum is $-50 \mathrm{nT}$ (Figure 2). The depth values vary from $1.62 \mathrm{~km}$ to $0.1 \mathrm{~km}$. The susceptibility values ranges from 0.021 to 2.193 SI units while the dip values have maximum of 177 degrees and a minimum of 65 degrees. The elongated part of the contour $\mathbf{f}$ indicates contact structure (Figure 2). It passes through three major closures (Figure 2); in the first closure, up to about $8 \mathrm{~km}$ (Figure 2), no result was obtained.

Profile BB': The maximum magnetic intensity value along this profile is $30 \mathrm{nT}$ and minimum value is $-50 \mathrm{nT}$ (Figure2). The depth values along this profile ranges from 0.3 to $2.6 \mathrm{~km}$ approximately. The susceptibility contrast varies from $9.7 \times 10^{-4}$ to $1.308 \times 10^{-1}$ SI units (Table 2) approximately and the dip values have maximum of 173 degrees and minimum of 56 degrees.

Profile CC': This profile is located in the south eastern area of the map. This is the area of low magnetic field intensity, for example, the minimum value is $-150 \mathrm{nT}$ and the maximum value is about $49 \mathrm{nT}$ (Figure 2). The depth values vary from 0.3 to $0.5 \mathrm{~km}$ approximately. The dip values have a maximum of 158 degrees and minimum value is 55 degrees and susceptibility ranges from $6.7 \times 10^{-5}$ to $1.54 \times 10^{-4} \mathrm{~S}$.I units approximately. The contour $\mathbf{d}$ indicates dike body.

The minimum value of the depth to the top $(0.1 \mathrm{~km})$ and most of the values obtained by this study indicate the presence of shallow sources anomalies in the study area as it was reveled by the previous work [2]. Therefore, shallow source anomalies can be estimated adequately by the interpretation of the total aeromagnetic anomaly using Werner deconvolution method. The susceptibility value of $6.7 \times 10^{-5}$ SI unit obtained is closer to $6.1 \times 10^{-5} \mathrm{SI}$ unit obtained by Oniku et.,al [5]. All this comparisons shows that the interpretation of total magnetic field profile using Werner deconvolution technique can compute the depth to the top and susceptibility with reasonable accuracy.

Table 1: Profile AA' result

\begin{tabular}{|l|l|l|l|l|}
\hline S/N & Distance/km & Depth$(\mathbf{k m})$ & Susceptibility (S.I Unit) & Shape \\
\hline 1 & 18.4 & 0.2 & $\mathbf{0 . 0 2 0 6}$ & Contact \\
\hline 2 & 20.1 & 1.4 & 0.0325 & Dike \\
\hline 3 & 30.9 & 0.8 & 0.2296 & Dike \\
\hline 4 & 32.2 & $\mathbf{0 . 1}$ & 1.3979 & Dike \\
\hline 5 & 37.5 & 1.0 & 0.1464 & Dike \\
\hline 6 & 42.1 & $\mathbf{1 . 6}$ & $\mathbf{2 . 1 9 3 1}$ & Contact \\
\hline
\end{tabular}

Table 2: Profile BB' result

\begin{tabular}{|l|l|l|l|l|}
\hline S/N & Distance/km & Depth(km) & Susceptibility (S.I Unit) & Shape \\
\hline 1 & 18.4 & 0.2 & $\mathbf{0 . 0 0 0 9 7}$ & Contact \\
\hline 2 & 22.7 & 0.4 & 0.0002 & Dike \\
\hline 3 & 29.3 & $\mathbf{2 . 6}$ & $\mathbf{0 . 1 3 0 8}$ & Dike \\
\hline 4 & 32.1 & 0.6 & 0.0008 & Contact \\
\hline 5 & 42.1 & 1.6 & 0.0103 & Contact \\
\hline 6 & 44.6 & 1.4 & 0.0854 & Dike \\
\hline 7 & 52.9 & $\mathbf{0 . 3}$ & 0.0012 & Dike \\
\hline
\end{tabular}


Table 3: Profile CC' result

\begin{tabular}{|l|l|l|l|l|}
\hline S/N & Distance/km & Depth(km) & $\begin{array}{l}\text { Susceptibility } \\
\text { (S.I Unit) }\end{array}$ & Shape \\
\hline 1. & 18.2 & $\mathbf{0 . 3}$ & $\mathbf{0 . 0 0 0 1 5 4}$ & Contact \\
\hline 2. & 18.4 & 0.2 & $\mathbf{6 . 7 \times 1 0 ^ { - 5 }}$ & Contact \\
\hline 3. & 22.7 & $\mathbf{0 . 5}$ & 0.000138 & Dike \\
\hline
\end{tabular}

\section{Conclusion}

The automatic method of direct interpretation of magnetic profile using Werner's equation is fast, accurate and very effective. Shallow source anomalies and magnetic susceptibility can be estimated adequately using this method. It can be applied to real data and obtain reasonable result. The depth to magnetic source values obtained from the data of Zaria area using Werner deconvolution method vary from 0.1 to $2.6 \mathrm{~km}$ while the susceptibility vary from $6.7 \times 10^{-5}$ to 2.193 S.I unit approximately.

\section{Acknowledgements}

Thanks are due to the management of Umaru Musa Yar'adua University Katsina for the encouragement to carry out this research. The authors wish to acknowledge the support given by the department of Physics Ahmadu Bello University Zaria for providing the software used in this research.

\section{References}

[1] Telford, W.M., Geldart, L.P., Sheriff, R.E., 2001. Applied Geophysics Second Edition, University press Cambridge, page: 62-134.

[2] Ibrahim B., 1992. Ground Magnetic investigation of the Kubani basin, Zaria. Unpublished M.Sc Thesis A.B.U Zaria.

[3] Lawal K.M. 1998. The application of reduction to the pole technique for the Interpretation of aeromagnetic data of Zaria area north central Nigeria. Unpublished M.Sc. thesis A.B.U. Zaria.

[4] Oniku, S.A, Lawal, K.M and Osazuwa, I.B, 2012. Studies of Rock Magnetic Properties of Kufena Hill in Zaria Area Northern Nigeria. Journal of Emerging Trends in Engineering and Applied Sciences(JETEAS) 3(1): 108-113.

[5] Geological Survey of Nigeria, GSN, 1994. Geological map of Zaria area, sheet 21.

[6] Geological Survey of Nigeria, GSN, 1974. Airborne Magnetometer Survey Map of Contours of Total magnetic Field Intensity. Sheet 102, Zaria area.

[7] Hartman, R.R., Tesky, D.J., and Friedberg, J.L., 1971. A system for rapid digital Aeromagnetic Interpretation. Geophysics, 36(5): $891-918$

[8] Umego M.N., 1990. Structural interpretation of gravity and aeromagneticAnomalies over Sokoto basin, north western Nigeria. Unpublished P.H.D. thesis A.B.U. Zaria.

[9] Jain S. 1976. An automatic method of direct interpretation of magnetic Profiles. Geophysics, 41(3):531-541. 